

\title{
Tribological origin of squeal noise in lubricated elastomer/glass contact
}

Anton Rusanov, Denis Mazuyer, Joël Perret Liaudet, Alain Le Bot, Matthieu Guibert, Julian Le Rouzic

\section{- To cite this version:}

Anton Rusanov, Denis Mazuyer, Joël Perret Liaudet, Alain Le Bot, Matthieu Guibert, et al.. Tribological origin of squeal noise in lubricated elastomer/glass contact. Acoustics 2012, Apr 2012, Nantes, France. hal-00811118

\section{HAL Id: hal-00811118 https://hal.science/hal-00811118}

Submitted on 23 Apr 2012

HAL is a multi-disciplinary open access archive for the deposit and dissemination of scientific research documents, whether they are published or not. The documents may come from teaching and research institutions in France or abroad, or from public or private research centers.
L'archive ouverte pluridisciplinaire HAL, est destinée au dépôt et à la diffusion de documents scientifiques de niveau recherche, publiés ou non, émanant des établissements d'enseignement et de recherche français ou étrangers, des laboratoires publics ou privés. 


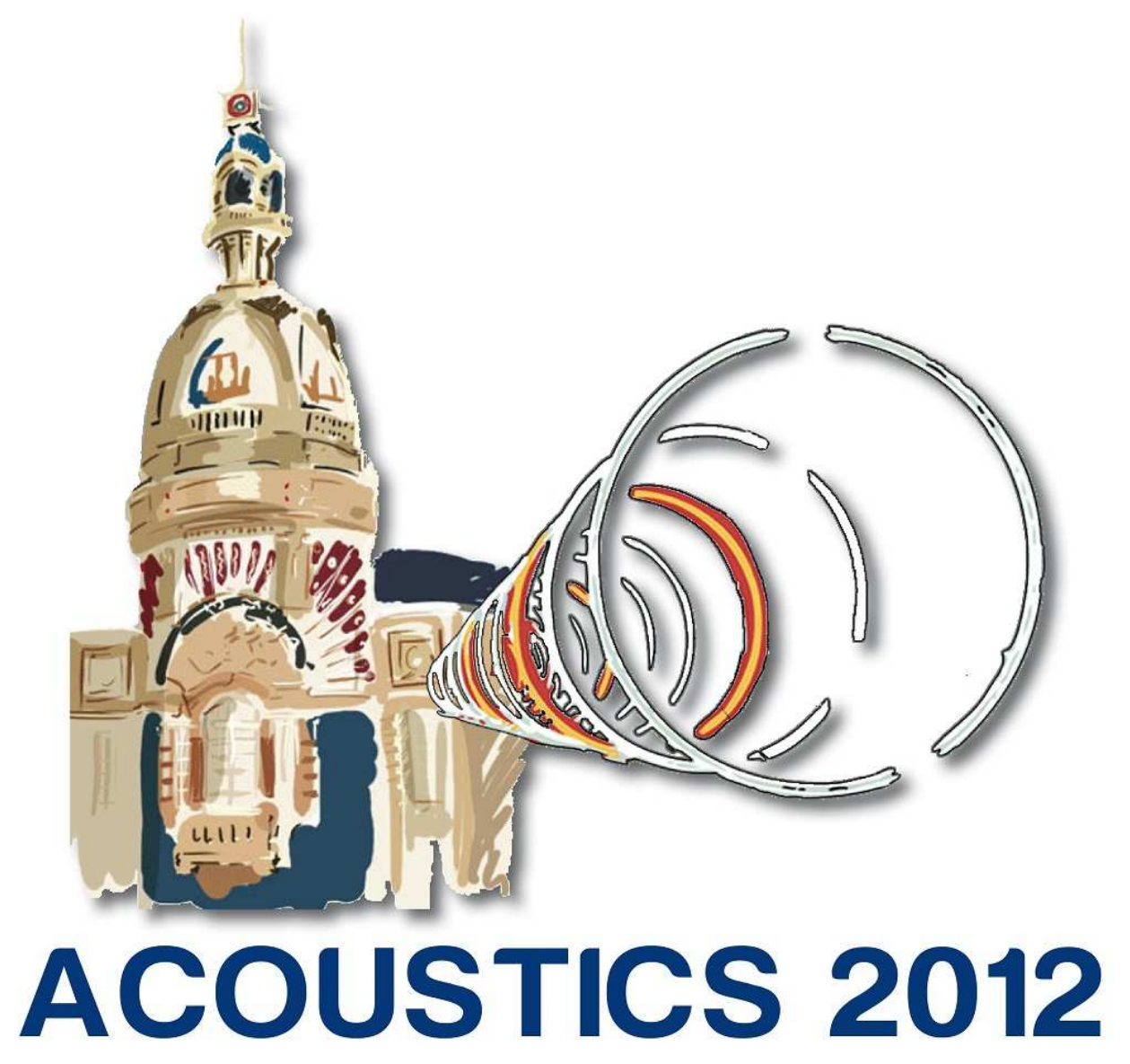

\section{Tribological origin of squeal noise in lubricated elastomer/glass contact}

A. Rusanov, D. Mazuyer, J. Perret Liaudet, A. Le Bot, M. Guibert and J. Le Rouzic

Laboratoire de Tribologie et Dynamique des Systèmes, 36 Avenue Guy de Collongue, 69134 Ecully Cedex

anton.rusanov@ec-lyon.fr 
This study investigates the tribological conditions in water lubricated elastomer/glass contact which lead to selfexcited vibration and squealing noise. Friction tests were performed using a specific experimental device "Lug". In the experiments, friction forces and vibration velocity have been properly measured for a wide range of relative velocities. The resulting friction coefficient as a function of sliding velocity well fits Stribeck's law. Instabilities appear during the transition between static and hydrodynamic regimes. Actually the negative slope of the friction force as function of relative velocity in the mixed lubrication regime enables the system to become unstable. Knowing the damping ratio of the oscillator, it is then possible to predict from the friction force measurements the range of velocities that lead to instabilities.

\section{Introduction}

Self-excited vibrations are observed in many technical applications. The occurrence of self-excited vibration in a physical system is associated with the stability of equilibrium position of the system [1]. Friction-induced vibration is an example of self-excited vibration.

A vibrating system is commonly modeled with a mass supported by a spring and carried by a moving belt through friction (Figure 1). In this approach it is noticed that friction coefficient decreasing with velocity can make the system unstable.

In this article a water lubricated elastomer/glass contact which leads to self-excited vibration is studied.

\section{Modeling}

Classic model of vibrating system is considered in Figure 1. A solid of mass $m$ in position $x$ is fixed to a wall through a spring of stiffness $k$ and viscous damping ratio $c$. This solid is sliding on a convey belt with an absolute speed $V$.

Friction at the contact of the solid and the belt occurs with tangential friction force $T(v)$ depending on the relative velocity $v=V-\dot{x}$. The governing equation of motion of the mass is:

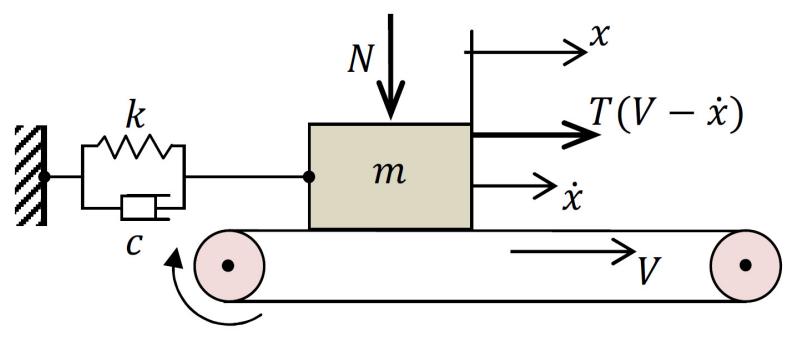

Figure 1: Classic model of friction-induced vibration system.

$$
\left\{\begin{array}{ll}
m \ddot{x}+c \dot{x}+k x=T(V-\dot{x}) & \text { for } x \neq V \\
\dot{x}=V & \text { for }|k x| \leq T(0)
\end{array}\right. \text {. }
$$

The first equation is applied in case if the relative velocity is non-zero $\dot{x} \neq \mathrm{V}$, i.e. for slip condition, whereas the second equation applies for stick condition which is possible if the elastic force $k x$ is lower than the maximum admissible static friction force $T(0)=T \mathrm{~s}$. Focusing on the slip regime and by the knowledge of the applied normal force $\mathrm{N}$, the friction force is expressed as:

$$
T(v)=\mu_{k}(v) N \operatorname{sgn}(v) .
$$

The stability analysis of such a system leads to the following conclusion. The system is stable whenever,

$$
\frac{\partial T}{\partial v}>-c
$$

and becomes unstable through a Hopf bifurcation of second kind otherwise [2].

\section{Experimental setup}

In order to verify the relevance of the above theoretical results, we have performed friction and vibration measurements on a sliding glass/elastomer contact lubricated with water.

Friction experiments were performed using an original tribometer named "Lug". Its schematic diagram is shown in fig. 2 .

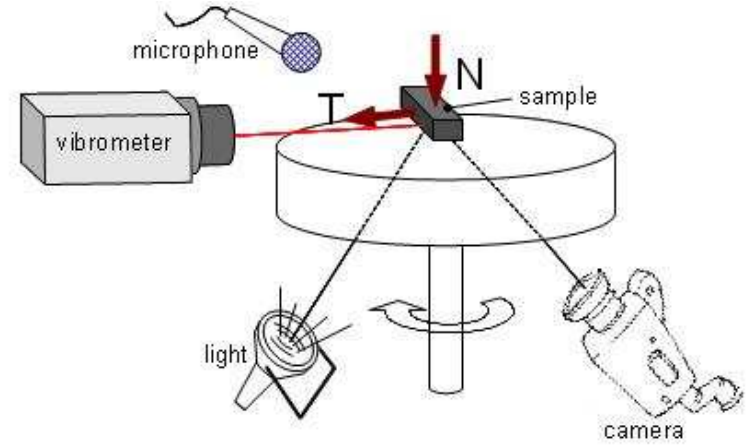

Figure 2: Schematic diagram of the experimental device.

An elastomer sample is put into contact against a rotating glass disk. The rotating speed is imposed and the resulting vibration is measured by a laser beam vibrometer and observed by optical interferometry.

\section{$4 \quad$ Results and discussion}

The sliding speed ranges from $30 \mathrm{~mm} / \mathrm{s}$ to $1 \mathrm{~m} / \mathrm{s}$. In Fig. 3 is shown the friction coefficient and vibration velocity versus sliding speed. It can be seen that the vibration is non existent at slow sliding speed. Its maximum is reached near $300 \mathrm{mmm} / \mathrm{s}$ and then decreases about $600 \mathrm{~mm} / \mathrm{s}$. This behaviour must be related to the decreasing of the friction coefficient versus sliding speed (black curve). It can be observed that the maximum of the vibration velocity is reached for the maximum of friction coefficient slope. 


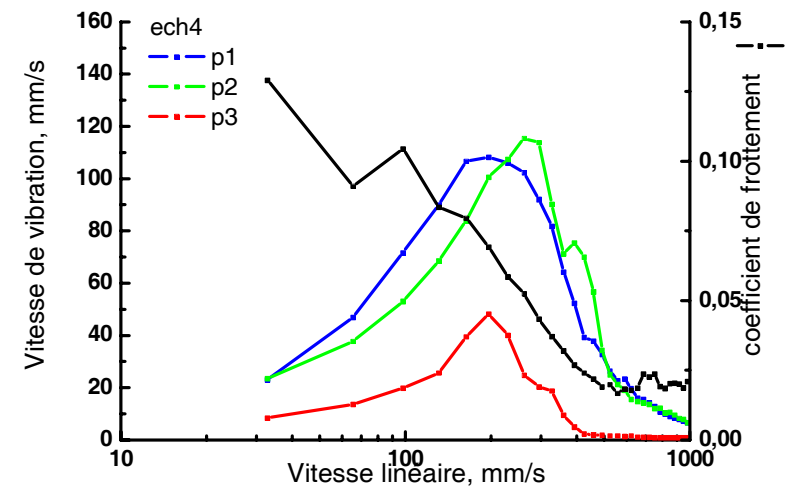

Figure 3: Friction coefficient and vibration velocity versus sliding speed

In Fig. 4 is shown a typical view of the elastomer/glass contact through the glass disk. The contact is found to be constituted by many spots. This interface is a population of events whose statistical ensemble can explain the macrsocopic behaviour of the contact [3].



Figure 4: Photo of the elastomer/glass contact.

\section{Conclusion}

The elastomer/glass contact may give rise to a mechanical instability which leads to squeal noise. This instability is well explained by the classical conveyor-belt model. The existence of a Hopf bifurcation is confirmed by the performed experiments. Furthermore, the optical observation of contact highlights that complexity of the friction law is strongly connected to the statistical behaviour of the spot population,.

\section{Acknowledgments}

The authors acknowledge the LAboratoire d'excellence Celya and the Agence nationale de la recherche (ANR) for their financial support under the contact ANR-10-LABX60.

\section{References}

[1] A. M. Liapunov, The General Problem of the Stability of Motion, Taylor \& Francis

[2] J Le Rouzic, J Perret-Liaudet, A. Carbonelli, A. Le Bot, D. Mazuyer. Some experimental and analytical results on self-excited vibrations of a dynamic sliding system in the case of Stribeck law for friction coefficient. ASME 2011.

[3] F. Deleau, D. Mazuyer and A. Koenen. Sliding friction at elastomer/glass contact: Influence of the wetting conditions and instability analysis. Tribology international, 42, pp. 149-159, 2009. 